\title{
Competencies of technical-vocational teachers of the College of Education: Bases for comprehensive training program
}

\author{
Jovita E. Villanueva \\ College of Education, Bulacan State University, Philippines.
}

Accepted 24 September, 2018

\begin{abstract}
The Bulacan State University evolved from being a school of arts and trades before becoming a state university as it is now. The university charter mandates that the institution shall provide higher technical education primarily to the people of the province of Bulacan and its neighboring provinces. Bulacan State University is known in producing highly skilled graduates in terms of garments technology, food technology, cosmetology, building technology and other technical vocational areas that was because faculty members then where experts of a specialized field. When a paradigm shift in the education system took place, teachers of technical vocational education became jack of all trade because they were mostly graduates of a major known as technology and livelihood education. As a result when referring to specialized set of competency standards set by Technical Skills Development Authority (TESDA) many teachers lack the needed competency. With the retirement of many specialized teachers of Bulacan State University what were left to teach were teachers who where actually graduates of Technology and Livelihood Education. Since TESDA has provided competencies based on the international standard the researcher would like to find out if the level of competencies of the incumbent teachers as regard to the competencies set by Technical Skills Development Authority (TESDA). These competencies were pertaining to those defined by TESDA in each of each test packages being used in assessment for the issuance of National Certification I-IV. The instrument developed made used of the competencies identified by Technical Education Skills Development Authority (TESDA). Research instrument was duly evaluated and validated by experts in the field of technical-vocational education. Respondents of the study were all technical vocational teachers of Bulacan State University from the college of education including laboratory high school. Data gathered were tallied, tabulated using frequency, percentage and weighted mean. Result indicated that majority of the technical- vocational teachers were moderately competent in the various competencies identified by TESDA as indicated by the overall weighted mean of 2.73 . Technical - vocational education faculty members of the university is ready for the shift of the Philippine education system but further training is highly suggested. As a result an intervention program in form of training will be the output of this research.
\end{abstract}

Keywords: Competencies, technical vocational, training program.

*Corresponding author. E-amil: hovy27@yahoo.com.

\section{INTRODUCTION}

Technical-vocational education is not new in Bulacan State University since its humble beginning was from being a school of arts and trades until becoming a state university. The university then produced highly skilled graduates in technician education because teachers then were graduates of specialized fields like cosmetology, woodworking, electronics, automotive, drafting, welding, plumbing and many others. However, due to the changes in educational system the university's teachers became mostly graduates of technology and livelihood education. 
The course does not prepare graduates to become expert in one area but rather students under it has to take various subjects making the graduate jack of all trade instead of concentrating on one area. Due to retirement of many expert teachers, most of the teachers handling technical- vocational educational subjects were no longer expert in one particular area since they had to pass through all areas of technology and livelihood education. With this observation the researcher conducted the study to find out what is the level of competency of technicalvocational teachers of the college of education based on the competencies set by TESDA.

$\mathrm{K}$ to 12 curriculum has technical-vocational track and therefore those teachers handling the subjects in said track must be experts or specialist.

In the $\mathrm{K}$ to 12 curriculum, the students of grade 7 will have to pass through all four (4) areas of technology and livelihood education but need to concentrate in one area once they reached grade 9 . From grade 9 to grade 12 the student will focus on studying only one area of the technical vocational track. Since the students will undergo comprehensive training in one area of technicalvocational track, after graduation they may be given a chance to be recognized as technician or professionals in other country.

The same applies to Bachelor of Technical Teacher Education since they will teaching specialized field it is but ideal that teachers handling their major subjects be experts as well.

In line with this, teachers handling the Bachelor of Technical Teacher Education and technical-vocational subjects in the laboratory high school should gear up to meet international standards. Technical-vocational teachers need to take the national certification program ofTechnical Education Skills and Development Authority (TESDA) for them to be qualified to teach the various technical vocational subjects under the Bachelor of Technical Teacher Education program.

\section{Statement of the problem}

The general problem of the study is: How may the competencies Technical-Vocational Education faculty members of the college of education of Bulacan State University be assessed as bases for comprehensive training?

Specifically, the study seeks to answer the following question:

1. How may the faculty members' profile be described in terms of the following:

1.1 educational background and;

1.2 field of specialization?

2. How may the competencies of Technical Vocational Education teachers be measured based on the National Certification criteria?

\subsection{Agri- Fishery;}

\author{
2.1.1 Animal Production \\ 2.1.2 Horticulture \\ 2.2 Home Economics; \\ 2.2.1 Garments Technology \\ 2.2.2 Beauty Care and Nail Care \\ 2.2.3 Bread and Pastry Production \\ 2.3 Industrial Arts \\ 2.3.1 Consumer Electronics Servicing \\ 2.3.2 Drafting Technology \\ 2.3.3 Woodworking \\ 2.3.4 Auto servicing \\ 2.4 Entrepreneurship \\ 2.4.1 Bookkeeping?
}

3. Based on the result of the study, what training may be initiated to enhance the competencies of faculty members for the national certification?

The result of this study is believed to be beneficial to the following:

The results of this research will be beneficial to the technical-vocational faculty members since they will be given an assessment activity that will gauge their level of competencies in the different areas of the technicalvocational tracks.

This will give an idea to the administrators what type of training should be conducted to prepare the faculty members towards the requirements of the National Certifications which is a requirement of the Philippine Qualifications Framework. Result will also be used as basis for budget allocation in the professional development of the faculty members.

Should there be another research to be conducted along technical-vocational education, the researcher suggests that other aspects not included in this study be given attention by future researchers.

Respondents of the study were all seventeen (17) technical-vocational education teachers of the college of education including laboratory high school.

\section{Competency}

Competency (mistakenly popularly known as Competence) is a standardized requirement for an individual to perform a specific job properly. According to Wikipedia (2016), competence encompasses a combination of knowledge, skills, and behavior utilized to improve performance. More generally, competency is the state or quality of being adequately or well-qualified, having the abilityto perform a specific role.

For instance, management competency includes the traits of systems thinking and emotional intelligence, and skills in influence and negotiation. A person possesses a competency as long as the skills, abilities and knowledge that constitute that competency is a part of that person, enabling the person to perform effective action within a certain workplace environment. Therefore, one might not 
lose knowledge, a skill, or an ability, but still lose a competency if what is needed to do a job well changes.

According to Wikipedia (2016), competency is also used to work with more general descriptions of the requirements of human beings in organizations and communities. Examples are education and other organizations that want to have a general language to tell what a graduate of an education must be able to do in order to graduate or what a member of an organization is required to be able to do in order to be considered competent. An important detail of this approach is that all competencies have to be action competencies, which means that a person shows in action that that person is competent. In the military, the training system for this kind of competency is called artificial experience, which is the basis for all simulators.

Furthermore, Wikipedia (2016) cited that competency is shown in action in a situation and context that might be different the next time a person has to act. In emergency contexts, competent people will react to the situation following behaviors they have previously found to succeed, hopefully to good effect. To be competent, a person needs to be able to interpret the situation in the context and to have a repertoire of possible actions to take and have trained in the possible actions in the repertoire, if this is relevant. Regardless of training, competency grows through experience and the extent of an individual to learn and adapt.

However, there has been much discussion among academics about the issue of definitions. The concept of competency has different meanings, and continues to remain one of the most diffused terms in the management development sector, and the organizational and occupational literature.

Competencies have been prepared in order to determine real working conditions which may have different degrees of complexity, variety, and autonomy. Such degrees represent the different levels of competency required for the performance of a job.

Within the competency standardization and certification system of the United Kingdom, levels have been structured after the analysis of productive functions. The objective was to define a reference framework which could be broad enough to maintain the sense of flexibility and keep individuals' possibilities of transferring their competencies to new labour contexts.

The definition of levels of competency is considered within the structure of standardized systems of labour competency certification. By using this structure, it is feasible to view the possibilities of promotion and transfer among different qualifications.

Boahin (2018) the term 'competence' and 'competency' are confused in the literature and defined from several viewpoints from different researchers. Most of these definitions are centred around "descriptions of work tasks", that is; what a person has to do in a job and "description of behaviour" i.e; how a person does their job. Furthermore he cited that competence is the ability based on work task' and competency(ies) as ability based on behaviour (Whiddett and Hollyforde, 2003). Meanwhile, he further cited the statement of Armstrong (2005) that argues that while competency is a personrelated concept, competence is a work-related concept. Supporting the argument, Kouwenhoven (2003) said that 'Competency' is the capability to apply an integrated combination of knowledge, skills and attitudes to perform a task in a given context whilst competence connotes the capacity to accomplish 'up to standard' the key occupational tasks that characterise a profession. Simply put, competences are usually role or job-specific while competencies can cover a wide range of different jobs ((Whiddett and Hollyforde, 2003). It can deduced from the foregoing that competency defines the necessary knowledge, skills, experience and attributes to carry out specific function effectively whilst competence connotes the capability to effectively perform a given task at both individual and organisational levels using required skills, traits, characteristics and behaviours.

Furthermore Boahin emphasized that in recent times, the economy of every nation needs adaptable and flexible workers, supervisor, trainers, bureaucrats and managers. Therefore, the need for routine, technical task skills is declining and that economic aims of every nations are becoming more strategically focused with holistic work approach. Many progressive employers are recognising that the narrow specific approaches to job training are far from adequate to meet their future strategic needs. Competence therefore should be described in general terms as being able to perform whole work roles rather than just specific skills and tasks to the standards expected in employment in real working environments. It must be emphasized that acquiring and developing competences is more than learning a set of skills (Kouwenhoven, 2009).

Meanwhile Wahha (retrieved 9/20/2018) discussed in his article that competency is defined as the individual's ability to use, apply and demonstrate a group of related awareness, knowledge, skills and attitudes in order to perform tasks and duties successfully and which can be measured against well-accepted standards (levels) required in employment as well as assessed against provided evidences at work location. The competency affects both individual's job responsibility and performance on the job and usually fall into two categories, namely technical and behavioral. According to him, the key aspects of the definition of competency are: (1) any job / occupation can be effectively and sufficiently described in terms of the tasks that successful workers in that occupation perform, (2) all tasks have direct implications for the awareness, knowledge, skills, and attitudes, (3) competencies that workers / trainees must acquire in order to perform the tasks correctly, (4) assessment is made on how the individual is actually performing work, (5) an individual is 
incompetent no matter how much knowledge he has, as long as he can't apply his knowledge and skills appropriately at work location, (6) the assessment must be objective by conducting it against defined Competency Standards (Levels).

The definition of competency implies a more formal, objective process of assessing performance by clearly knowing what is being assessed and how it is assessed. This approach is quite different than most of the past performance assessment practices utilized in the industry.

Wahha further reiterated that one of the most important and significant developments in the Technical Vocation Education and Training (TVET), was the development of Competence Based Standards to support the design of training programmes and curricula. According to Wahha the instrument developed to enable this change is the concept of an occupational or educational 'standard (level)'. The standard elaborates the level of competence required to perform successfully in an occupation and that description is used, in turn, to develop a closely aligned curriculum.

\section{RESEARCH METHODS}

I

This study employs the descriptive survey method of research. It is the most popular method of gathering data or information through the use of questionnaires, unstructured interview and observations.

Research questionnaire was the main tool used in data gathering for this study. A research questionnaire was prepared and used in gathering information from the respondents. One set of questionnaire was answered by the technical-vocational teacher- respondents. Research instruments were taken from the competencies identified by Technical Education Skills and Development Authority (TESDA). After the research instrument was drafted, the instrument was validated by five (5) experts technicalvocational and an expert in statistics and research writing to make the instrument more credible.

The questionnaire for technical-vocational teachers had two (2) parts.

Part I covered the profile of the faculty respondents, such as age, gender, length of teaching experience, relevant trainings and seminars and field of specialization.

Part II covered the technical-vocational teachers' level of competencies in the various areas like animal production, horticulture, garments technology, beauty care (nail care), bread and pastry production, consumer electronics servicing, drafting technology, woodworking, auto servicing and bookkeeping.

Respondents were all seventeen (17) technicalvocational teachers of the college of education including laboratory high school.

In taking initial data like the population of technical- vocational teachers the data from the office of the Dean was used. Permission to conduct the study was sourced from the college Dean. Once approved, the questionnaires were distributed personally to all seventeen (17) teacher respondents.

For the profile of the technical-vocational teachers' respondents the frequency and percentage were used to describe the data. In gauging the level of competencies of technical-vocational education teachers the weighted mean was used.

The scale in Table 1 served as guide in identifying the level of competencies of the technical-vocational education teachers.

Table 1. Scale.

\begin{tabular}{ll}
\hline Range & Verbal interpretation \\
\hline $4.51-5.0$ & Highly competent \\
$3.51-4.50$ & Competent \\
$2.51-3.50$ & Moderately competent \\
$1.51-2.50$ & Slightly competent \\
$1.0-1.50$ & Not competent \\
\hline
\end{tabular}

\section{RESULTS AND DISCUSSION}

In terms of the educational qualification most the respondents were masters degree holder as indicated in the frequency of 9 or $52.94 \%$ while the bachelor's degree and doctoral degree both posted a frequency of 4 or $23.52 \%$ and most of the respondents were of various majors like garments technology with frequency of 2 or $11.76 \%$, food technology 3 or $17.64 \%$, drafting technology with 4 or $23.52 \%$, electronics/electrical with 2 or $11.76 \%$, work education with 2 or $11.76 \%$, technology and livelihood education with 3 or 17.64 and cosmetology with 1 or $5.8 \%$ (Table 2).

In animal production, the item that registered the lowest is item number 12 which asked about competency in selection and management of goats and sheep with a weighted mean of 2.35 moderately competent while the highest is competency in the selection and use of farm tools with a weighted mean of 2.76 also moderately competent which resulted to the grand mean of 2.59 interpreted as moderately competent (Table 3). The result opposes the competency stated in the Arkansas Teaching Standard for Teachers of Agriculture for grades 7-12 which stated that teachers of agriculture should have the ability to classify, evaluate, and select animals based on anatomical and physiological characteristics. Though the standard cited was not on the Philippine context it is believed that teachers competencies in agriculture be at par with other countries.

In the area of horticulture, the lowest mean were recorded to the competencies in performing preventive 
Table 2. Profile of the respondents.

\begin{tabular}{lcc}
\hline Parameter & Frequency & Percentage \\
\hline Degree level & & \\
Doctorate & 4 & 23.52 \\
Masters & 9 & 52.94 \\
Baccalaureate & 4 & 23.52 \\
Total & 17 & 100 \\
& & \\
Major/ field of specialization & & \\
Garments Technology & 2 & 11.76 \\
Food Technology & 3 & 17.64 \\
Drafting Technology & 3 & 23.52 \\
Electronics/ Electrical Technology & 2 & 11.76 \\
Work Education & 2 & 11.76 \\
Technology and Livelihood Education & 3 & 17.64 \\
Automotive Technology & 1 & 5.8 \\
Cosmetology & 1 & 5.8 \\
Total & 17 & 100 \\
\hline
\end{tabular}

Table 3. Weighted mean for competency in Agriculture.

\begin{tabular}{lcl}
\hline Competencies & WM & Verbal Interpretation \\
\hline A.AGRICULTURE & & \\
ANIMAL PRODUCTION & & \\
1. Select and use farm tools. & 2.76 & Moderately Competent \\
2. Select and operate farm equipment. & 2.59 & Moderately Competent \\
3. Perform preventive maintenance. & 2.65 & Moderately Competent \\
4. Perform estimation. & 2.65 & Moderately Competent \\
5. Perform basic workplace calculation. & 2.53 & Moderately Competent \\
6. Select and procure stock. & 2.71 & Moderately Competent \\
7. Maintain optional environment for poultry. & 2.65 & Moderately Competent \\
8. Observe and assess chick health. & 2.59 & Moderately Competent \\
9. Select brood/ layer stock. & 2.65 & Moderately Competent \\
10. Perform pre and post laying activities. & 2.59 & Moderately Competent \\
11. Perform preventive and therapeutic measures. & 2.47 & Slightly Competent \\
12. Select and manage breeders' goats and sheep. & 2.35 & Slightly Competent \\
13. Provide feed and implement feeding practices. & 2.59 & Moderately Competent \\
14. Implement herd health program. & 2.53 & Moderately Competent \\
15 Maintain and analyze records & 2.65 & Moderately Competent \\
Grand Mean & 2.59 & Moderately Competent \\
\hline
\end{tabular}

maintenance, perform basic workplace calculation and apply corrective measures, they all registered a mean of 2.53 while the highest were determining areas of concern for safety measures items (items $16,17,18$ ) with a mean of 2.88 which is interpreted to be moderately competent. The grand mean is 2.67 moderately competent (Table 4). This result supports the findings of Svensson et al. (2013) that common causes of increased occupational fatalities among migrant farm workers is that because they have little training in accident prevention, as a result they are more prone to accidents such as crushing from farm equipment, accidental slicing with hand labour tools, and falling from ladders. Therefore, falls, cuts, amputations, and other injuries are common risks that migrant farm workers face in their daily work due to lack of training.

For garments technology, the teachers perceived that their competency with the highest weighted mean were identifying tools and equipment and obtaining measurements both got 3.53 with a verbal interpretation of competent and the competency they perceived to be 
Table 4. Weighted mean as competency in horticulture.

\begin{tabular}{lll}
\hline Horticulture & WM & Verbal Interpretation \\
\hline 16. Determine areas of concern for safety measures. & 2.88 & Moderately Competent \\
17. Apply appropriate safety measures. & 2.88 & Moderately Competent \\
18. Safekeep/maintain/dispose tools, materials and outfit. & 2.88 & Moderately Competent \\
19. Prepare and use farm tools. & 2.59 & Moderately Competent \\
20. Perform preventive maintenance and procedures/ practices. & 2.53 & Moderately Competent \\
21. Perform estimation. & 2.59 & Moderately Competent \\
22. Perform basic workplace calculation. & 2.53 & Moderately Competent \\
23. Apply corrective measures as necessary. & 2.53 & Moderately Competent \\
Grand Mean & 2.67 & Moderately Competent \\
\hline
\end{tabular}

Table 5. Weighted mean as competency in garments technology.

\begin{tabular}{lll}
\hline Garments technology & WM & Verbal Interpretation \\
\hline 24. Identify sewing tools and equipment. & 3.53 & Competent \\
25. Obtain measurements. & 3.53 & Competent \\
26. Perform simple calculations & 3.47 & Moderately Competent \\
27. Estimate appropriate quantities. & 3.41 & Moderately Competent \\
28. Sketch simple project design. & 3.35 & Moderately Competent \\
29. Produce simple project. & 3.41 & Moderately Competent \\
30. Operate machine and assess its performance. & 3.47 & Moderately Competent \\
31. Clean and lubricate machine. & 3.41 & Moderately Competent \\
32. Identify and evaluate hazards risks. & 3.41 & Moderately Competent \\
33. Control hazards and risks. & 3.41 & Moderately Competent \\
Grand Mean & 3.44 & Moderately Competent \\
\hline
\end{tabular}

their lowest was sketching simple project design with a mean of 3.35 equivalent to Moderately Competent and thereby having grand mean of 3.44 Moderately Competent (Table 5).

In the area of nail care, the competency with the lowest mean was creating basic nail design as shown in the mean of 3.29 equivalent to moderately competent and the competency with the highest mean were the competencies in terms of using and storing of nail care tools both registered a mean of 3.53 equivalent to competent (Table 6). The grand mean of 3.43 which is moderately competent.

For bread and pastry production the competency was the practice safe and hygienic handling, storage and disposal of food, beverage and materials with a mean of 3.24 and the competency with the lowest mean was on producing accurate and complete data according to the requirements as registered in the mean of 2.59 interpreted to be moderately complete. Moderately competent was the grand mean as shown in the mean of 2.94 (Table 7).

For the area of consumer electronics servicing, the area with the lowest registered mean was competency in interpreting technical drawing with a weighted mean of 2.06 and the competency with the highest mean was preparing hand tools as indicated in the mean of 2.47 with the verbal interpretation of moderately competent and with a grand mean of 2.3 (Table 8). The result supports the study of Chedi (2015) that there are difficulties faced by both learner and teacher of technical drawing and especially in the teaching and learning situation. Furthermore he cited that there is problem in visualization in the teaching of technical drawing.

In the field of drafting technology, the competency with highest mean was carrying out measurements and calculations as revealed in the mean of 3.0 equivalent to moderately competent and the lowest competency was ability to interpret drawings and plans with a mean of 2.71 . The grand mean was recorded to be 2.84 moderately competent (Table 9). Garmendia (2007) in his paper titled 'First-year engineering students' difficulties in visualization and drawing tasks cited in one of his findings that visualizing parts, meaning interpreting the views of an object which has been represented in a drawing", is a fundamental skill in engineering. He further stated, learning deficiencies and difficulties have been observed among engineering undergraduates, and there is a high failure rate in drawing courses.

For woodworking area (Table 10), a weighted mean of 2.94 moderately competent was registered at the 
Table 6. Weighted mean as to competency in nail care.

\begin{tabular}{lll}
\hline Beauty care (Nail care) & WM & Verbal Interpretation \\
\hline 34. Prepare necessary tools and equipment for the specific nail care activity. & 3.47 & Moderately Competent \\
35. Use nail care tools and equipment. & 3.53 & Competent \\
36. Check condition of nail care tools and equipment. & 3.47 & Moderately Competent \\
37. Perform basic preventive and corrective maintenance. & 3.47 & Moderately Competent \\
38. Store nail care tools and equipment. & 3.53 & Competent \\
39. Identify hazards and risks. & 3.47 & Moderately Competent \\
40. Evaluate and control hazards and risks. & 3.35 & Moderately Competent \\
41. Identify nail structure, shapes and nail diseases/ disorders. & 3.35 & Moderately Competent \\
42. Create basic nail design & 3.29 & Moderately Competent \\
Grand mean & 3.43 & Moderately Competent \\
\hline
\end{tabular}

Table 7. Weighted mean as to competency in bread and pastry.

\begin{tabular}{|c|c|c|}
\hline Bread and pastry production & WM & Verbal Interpretation \\
\hline 43. Identify and access key sources of information on the industry. & 3.0 & Moderately Competent \\
\hline 44. Access, apply and share industry information. & 2.94 & Moderately Competent \\
\hline 45. Update continuously relevant industry knowledge. & 2.94 & Moderately Competent \\
\hline 46. Practice personal grooming and hygiene. & 3.18 & Moderately Competent \\
\hline $\begin{array}{l}\text { 47. Practice safe and hygienic handling, storage and disposal of food, beverage and } \\
\text { materials. }\end{array}$ & 3.24 & Moderately Competent \\
\hline $\begin{array}{l}\text { 48. Identify and explain the functions, general features and capabilities of both hardware } \\
\text { and software. }\end{array}$ & 3.18 & Moderately Competent \\
\hline 49. Prepare and use appropriate hardware and software according to task requirement. & 3.0 & Moderately Competent \\
\hline 50. Use appropriate devices and procedures to transfer files/ data. & 2.88 & Moderately Competent \\
\hline 51. Produce accurate and complete data according to the requirements. & 2.59 & Moderately Competent \\
\hline 52. Maintain computer system & 2.76 & Moderately Competent \\
\hline 53. Practice workplace safety, security and hygiene systems, processes and operations. & 2.94 & Moderately Competent \\
\hline $\begin{array}{l}\text { 54. Respond appropriately to faults, problems and emergency situations in line with } \\
\text { enterprise guidelines. }\end{array}$ & 2.82 & Moderately Competent \\
\hline 55. Maintains safe personal presentation standards. & 2.88 & Moderately Competent \\
\hline $\begin{array}{l}\text { 56. Apply effective verbal and non- verbal communication skills to respond to customer } \\
\text { needs. }\end{array}$ & 2.88 & Moderately Competent \\
\hline 57. Provide prompt and quality service to customer. & 3.06 & Moderately Competent \\
\hline 58. Handles queries promptly and correctly in line with enterprise procedures. & 3.0 & Moderately Competent \\
\hline 59. Handles customer complaints, evaluation and recommendations. & 2.94 & Moderately Competent \\
\hline 60.Developing and updating industry knowledge. & 2.82 & Moderately Competent \\
\hline 61.Observing workplace hygiene procedure. & 3.06 & Moderately Competent \\
\hline 62. Performing computer Operations & 3.0 & Moderately Competent \\
\hline 63.Maintaning Computer and Equipment System & 3.0 & Moderately Competent \\
\hline 64.Performing Workplace and Safety Practices & 2.82 & Moderately Competent \\
\hline 65.Providing Effective Customer Service & 2.82 & Moderately Competent \\
\hline Grand Mean & 2.94 & Moderately Competent \\
\hline
\end{tabular}

competency pertaining to identifying materials and tools applicable to a specific job meanwhile the lowest mean was posted in the competency on identifying access, and interpret specification and manuals with a mean of 2.59 equivalent to moderately competent. The grand mean was 2.81 moderately competent. Such finding supports the study of Shih (1993) titled "A comparison of competencies required by the woodworking industry and those taught in industrial vocational senior high schools, as perceived by former students and teachers of woodworking in Taiwan, Republic of China" revealed that woodworking skills should include engineering drawing, woodworking drafting, and computer applications; and woodworking knowledge, viz., woodworking tools and 
Table 8. Weighted mean as to consumer electronics servicing.

\begin{tabular}{lll}
\hline Consumer electronics servicing & WM & Verbal Interpretation \\
\hline 66. Plan and prepare for task to be undertaken. & 2.35 & Slightly Competent \\
67. Prepare hand tools. & 2.47 & Slightly Competent \\
68. Use appropriate hand tools and equipment. & 2.41 & Slightly Competent \\
69. Maintain hand tools. & 2.41 & Slightly Competent \\
70. Select measuring instruments. & 2.47 & Slightly Competent \\
71. Carry out measurements and calculations. & 2.35 & Slightly Competent \\
72. Maintain measuring instruments. & 2.35 & Slightly Competent \\
73. Identify different kinds of technical drawings. & 2.29 & Slightly Competent \\
74. Interpret technical drawing. & 2.06 & Slightly Competent \\
75. Prepare/ make changes on electrical/ electronic schematic and drawings. & 2.12 & Slightly Competent \\
76. Assess quality/ receive materials. & 2.24 & Slightly Competent \\
77. Engage in quality improvement. & 2.29 & Slightly Competent \\
78. Plan and prepare for task to be undertaken. & 2.35 & Slightly Competent \\
79. Input data into computer. & 2.29 & Slightly Competent \\
80. Produce output/ data using computer system. & 2.24 & Slightly Competent \\
81. Use basic functions of web browser to locate information. & 2.35 & Slightly Competent \\
82. Maintain computer equipment and systems. & 2.29 & Slightly Competent \\
83. Plan and prepare for termination/ connection of electrical wiring/ electronics circuits. & 2.24 & Slightly Competent \\
84. Terminate/ connect wiring/ electronic circuit. & 2.35 & Slightly Competent \\
85. Test termination/ connections of electrical wiring and electronic circuit. & 2.35 & Slightly Competent \\
Grand mean & 2.31 & Slightly Competent \\
\hline
\end{tabular}

Table 9. Weighted mean as to competency in drafting technology.

\begin{tabular}{lll}
\hline Drafting technology & WM & Verbal Interpretation \\
\hline 86. Select measuring instruments. & 2.94 & Moderately Competent \\
87. Carry out measurements and calculations. & 3.00 & Moderately Competent \\
88. Analyzes signs, symbols and data. & 2.88 & Moderately Competent \\
89. Interpret technical drawings and plans. & 2.71 & Moderately Competent \\
90. Assess quality of received materials. & 2.71 & Moderately Competent \\
91. Assess own work. & 2.82 & Moderately Competent \\
92. Engage in quality improvement. & 2.88 & Moderately Competent \\
Grand Mean & 2.84 & Moderately Competent \\
\hline
\end{tabular}

Table 10. Weighted mean as to competency in woodworking.

\begin{tabular}{lll}
\hline Woodworking & WM & Verbal Interpretation \\
\hline 93. Identify materials and tools applicable to a specific & 2.94 & Moderately Competent \\
94. Request for appropriate materials and tools. & 2.82 & Moderately Competent \\
95. Receive and inspect materials. & 2.88 & Moderately Competent \\
96. Apply information in manual. & 2.88 & Moderately Competent \\
97. Store manuals. & 2.76 & Moderately Competent \\
98. Analyze signs, symbols and data. & 2.88 & Moderately Competent \\
99. Interpret technical drawing and plans. & 2.88 & Moderately Competent \\
100. Apply information in manual. & 2.82 & Moderately Competent \\
101. Carry out measurements and calculations. & 2.82 & Moderately Competent \\
102. Select measuring instruments. & 2.88 & Moderately Competent \\
103. Check conditions of tools and equipments. & 2.76 & Moderately Competent \\
104. Perform basic preventive maintenance. & 2.76 & Moderately Competent \\
105. Store tools and equipment. & 2.76 & Moderately Competent \\
106. Identify, access, and interpret specification/ manuals. & 2.59 & Moderately Competent \\
Grand Mean & 2.81 & Moderately Competent \\
\hline
\end{tabular}


Table 11. Weighted mean as to competency in auto-servicing.

\begin{tabular}{llc}
\hline Auto servicing & WM & Verbal Interpretation \\
\hline 107. Identify appropriate sealant/ adhesive. & 2.35 & Slightly Competent \\
108. Prepare surface for sealant/ adhesive application. & 2.18 & Slightly Competent \\
109. Store unused and dispose used sealant/ adhesive. & 2.18 & Slightly Competent \\
110. Prepare vehicle for driving. & 2.29 & Slightly Competent \\
111. Move and position vehicle. & 2.24 & Slightly Competent \\
112. Check the vehicle. & 2.24 & Slightly Competent \\
113. Select measuring instrument and carry out measurements and calculations. & 2.12 & Slightly Competent \\
114. Maintain measuring instruments. & 2.12 & Slightly Competent \\
115. Identify/ access manuals and interpret data and specification. & 2.12 & Slightly Competent \\
116. Apply information accessed in manual. & 2.12 & Slightly Competent \\
117. Store manual. & 2.18 & Slightly Competent \\
118. Identify the Type of Lubricant/coolant. & 2.24 & Slightly Competent \\
119. Use and apply Lubricant/coolant & 2.35 & Slightly Competent \\
120. Inspect /clean tools and shop equipment. & 2.29 & Slightly Competent \\
121. Store/arrange tools and shop equipment. & 2.35 & Slightly Competent \\
122. Dispose waste/used & 2.41 & Slightly Competent \\
123. Report damaged tools/Equipment & 2.41 & Slightly Competent \\
Grand Mean & 2.24 & Slightly Competent \\
\hline
\end{tabular}

Table 12. Weighted mean as to competency in entrepreneurship.

\begin{tabular}{llc}
\hline D. Entrepreneurship & WM & Verbal Interpretation \\
\hline BOOKKEEPING & & \\
124. Maintain a Professional image. & 2.24 & Slightly Competent \\
125. Meet client/customer requirements. & 2.24 & Slightly Competent \\
126. Build credibility with customers /clients. & 2.35 & Slightly Competent \\
127. Plan own workload. & 2.35 & Slightly Competent \\
128. Maintain quality of own performance. & 2.41 & Slightly Competent \\
129. Establish credibility with customers/clients. & 2.35 & Slightly Competent \\
130. Assess client service needs. & 2.29 & Slightly Competent \\
131. Assess own work. & 2.35 & Slightly Competent \\
132. Engage in quality improvement. & 2.35 & Slightly Competent \\
133. Identify and explain the functions, general features and capabilities of both & 2.24 & Slightly Competent \\
hardware and software. & 2.18 & Slightly Competent \\
134. Prepare and use appropriate hardware and software according to task requirement. & 2.29 & Slightly Competent \\
135. Use appropriate devices and procedures to transfer files/data. & 2.12 & Slightly Competent \\
136. Produce accurate and complete requirements. & 2.18 & Slightly Competent \\
137. Maintain computer system. & 2.11 & Slightly Competent \\
Grand Mean & &
\end{tabular}

machines, materials and layout finishes and finishing, furniture structure, introductory furniture design production estimation, shop layout and management, and mold engineering the cabinet making/interior.

In terms of auto servicing, the area with the highest mean were competencies on disposing waste and used materials and reporting of damaged tools and equipment both registered a mean of 2.41 on the other hand the competencies with the lowest means were maintaining measuring instruments, identify/ access manuals and interpret data and specification and apply information accessed in manual all registered a mean of 2.12 equivalent to slightly competent (Table 11). The grand mean for this area is 2.24 Slightly Competent.

Meanwhile for Table 12, area of bookkeeping, the competency that recorded the highest mean was maintain quality of own performance with a rating of 2.41 interpreted as slightly competent and the competency 
Table 13. Summary of area mean.

\begin{tabular}{lcl}
\hline Area & Mean & Interpretation \\
\hline Animal Production & 2.59 & Moderately Competent \\
Horticulture & 2.67 & Moderately Competent \\
Garments Technology & 3.54 & Moderately Competent \\
Nail Care & 3.43 & Moderately Competent \\
Bread and Pastry & 2.94 & Moderately Competent \\
Consumer Electronic Servicing & 2.31 & Slightly Competent \\
Drafting Technology & 2.84 & Moderately Competent \\
Woodworking & 2.81 & Moderately Competent \\
Auto Servicing & 2.24 & Slightly Competent \\
Bookkeeping & 2.11 & Slightly Competent \\
Overall Mean & 2.73 & Moderately Competent \\
\hline
\end{tabular}

with the lowest mean is the competency on producing accurate and complete requirements with a mean of 2.12 slightly competent. The summary of area mean is given in Table 13.

\section{CONCLUSION}

Most of the teachers handling technical-vocational education subjects were moderately competent on the different areas of the technical-vocational streamline of the $\mathrm{K}$ to 12 curriculum based on the competencies set by Technical Educations Skills Development Authority.

\section{RECOMMENDATIONS}

1. Technical-vocational education faculty of the university were already moderately competent in the competencies set by Technical Education Skills Development Authority however the university may still consider conducting comprehensive training in the various areas of the technical-vocational tracks of the $\mathrm{K}$ to 12 curriculum.

2. In-service teachers should be given in-service training in technical-vocational areas to meet the requirements of the Philippine Qualifications Framework.

3. The university may link with training providers and likewise develop facilities for training purposes.

4. Should there be another research to be conducted along this area, the researcher highly recommends that other factors there were not included in this study be considered by future researchers.

\section{REFERENCES}

Arkansas Teaching Standards for Teachers of Agriculture for Grade 712.

Boahin, P. (2018). Competency based curriculum: A framework for bridging the gap in teaching, assessment and the world of work. International Journal of Vocational and Technical Education Research, 4(2): 1-15.
Chedi, J. (2015). Technical drawing/ graphic skills acquisition for teaching and learning and challenges in technology education. Journal of Science, Technology and Education, 3(3): 128-132.

Garmendia, M. (2007). First-year engineering students' difficulties in visualization and drawing tasks. European Journal of Engineering Education, 32(3): 315-323.

Kouwenhoven, G. W. (2003). Designing for competence: towards a competence-based Curriculum for the faculty of Education of the Eduardo Mondlane University: Doctoral Dissertation. Enschede: Twente University.

Kouwenhoven, W. (2009). Competence-based curriculum development in Higher Education: A globalised concept. VU University Amsterdam, The Netherlands.

$\mathrm{K}$ to 12 Tool Kit, Department of Education 2012 http://www.tesda.gov.ph

Shih, K (1993). A Comparison of the Competency Required by the Woodworking Industry and those Taught in industrial Vocational Senior High Schools as Perceived by former students and Teachers of Woodworking in Taiwan, Republic of China: Unpublished Doctoral Dissertation.

Svensson, M., Urinboyev, R., Wigerfelt, S. A., Lundqvist, P., Littorin, M., Albin, M. (2013). Migrant Agricultural Workers and Their Socioeconomic, Occupational and Health Conditions-A Literature Review. http://dx.doi.org/10.2139/ssrn.2297559.

Citation: Villanueva, J. E. (2018). Competencies of technicalvocational teachers of the College of Education: Bases for comprehensive training program. African Educational Research Journal, 6(3): 203-212. 